\title{
MMP-2 and MMP-9 Expression in Canine Cutaneous Melanocytic Tumours: Evidence of a Relationship with Tumoural Malignancy
}

\author{
Isabel Pires, Joana Gomes, Justina Prada, \\ Dinora Pereira and Felisbina L. Queiroga
}

Additional information is available at the end of the chapter

\section{Introduction}

\subsection{Melanocytic tumours}

Melanocytic tumours derive from melanoblast and melanocyte transformation and occur both in humans and dogs [1-4]. These lesions are mainly found at skin, digits and oral cavity and eye $[2,5,6]$. Moreover, melanocytic tumours can be benign or malignant. Melanomas are aggressive tumours that can metastasize early in the course of the disease, both locally and in distant organs $[3,7,8]$. Whereas in mouth and eye, this type of tumour is generally malignant, at cutaneous level, and despite the difficulties of making a precise diagnosis, melanocytic tumours are usually benign. When malignant, they are very aggressive [3-5,8,9].

Generally, the tumour initially starts with a radial-growth phase, which can rapidly progress to a vertical-growth phase, a stage where melanoma cells have a high proliferation rate and a strong ability to metastasize [10]. Although early detection and improved surgical techniques had increase the patient survival, the prognosis of metastatic melanoma is still very poor due to the resistance to existing therapies $[10,11]$. Consequently, cutaneous melanoma, the most malignant tumour of the skin, still represents the leading cause of skin cancer deaths [10]; therefore, canine malignant melanoma is a life threatening disease, with up to $80 \%$ of affected dogs developing metastasis [12].

The similarities between human and canine melanoma, coupled with their similar environmental exposure, make spontaneous canine melanoma an excellent model in comparative pathology, for studying the correspondent disease in human counterpart [8,13-15]. These 
studies rely, primarily, on understanding the factors and mechanisms underlying tumour growth and dissemination, which, ultimately, allows the design and effective use of novel therapeutic strategies for cancer therapy $[4,10,11,16]$.

The major hallmarks of cancer include migration, invasion, metastasis and angiogenesis [17]. An event intrinsically associated with the initial process of tumour invasion is similar to the epithelial-mesenchymal transition (EMT), a highly conserved and fundamental process of morphological transition that occurs during developmental processes; during this event, epithelial cells down-regulate cell-cell adhesion molecules and acquire a mesenchymal phenotype with reduced intercellular interactions and increased migratory capacity $[17,18]$. In addition, for cancer cells being able to continue growing and start migrating, new blood vessels have to be created by angiogenesis, being the new vessels easily penetrable by tumour cells due to their elevated permeability and reduced resistance [17-21].

Under normal circumstances, the extracellular matrix (ECM) constitutes one of the natural barriers against tumour spread [11,22-24]. Therefore, as cell dissemination from the primary tumour includes invasion of surrounding tissue and basement membranes, intravasation into the lymphatic or blood circulation, adhesion and extravasation into distant organs, degradation and remodeling of ECM by proteolytic enzymes are essential for tumour metastasis $[5,17-19,25,26]$. Thus, proteolytic enzymes have been considered important factors and potential molecular markers associated with tumour growth and invasion in several types of cancer, including melanoma $[16,26,27]$, where prognostic markers are needed to predict the risk of progression, assess the clinical outcome and select optimal treatment strategies $[4,10,16]$.

\subsection{Matrix metalloproteinases}

Proteolytic enzymes can be classified as exopeptidases or endopeptidases, based on their ability to cleave terminal or internal peptide bonds, respectively [28]. Proteases are proteolytic enzymes present in all organisms in different sizes, shapes and catalytic properties, but with the common ability to hydrolyze the internal bonds of various peptides $[27,29]$.

Most proteases are classified as serine, cysteine, aspartic or matrix metalloproteinases (MMPs), according to their catalytic mechanism and inhibitor sensitivities [28,30]. The MMPs or matrixins were first described in 1962 by Gross and Lapiere [22,23] and are mostly known by their ability to degrade components of the ECM. This family of endoproteases has been considered essential in a number of normal physiologic processes as well as pathological events [24]; therefore, over the last years, the structure and function of MMPs and their roles in pathological processes, including cancer, have been intensively investigated in both human and veterinary medical research $[19,27,29,31,32]$.

Currently, more than 25 different types of MMPs have been identified among vertebrates and the majority is expressed and has similar functions both in humans and dogs [16,27-29,33]. Nevertheless, MMPs have many similarities in their structure, sharing considerable homology within their major domains, including signal peptide, propeptide, catalytic and hemopexinlike domains $[16,23,27,34]$. Additionally, MMPs are zinc- and calcium-dependent for functional activity and, according to substrate specificities, domain organization and sequence 
similarities, they are classified into six groups: collagenases, stromelysins, matrilysins, membrane-type MMPs (MT-MMPs), gelatinases and other MMPs [16,23,27,35].

Collagenases are represented by MMP-1, MMP-8 and MMM-13 or collagenase $-1,-2$ and -3, respectively. Preferentially, they have affinity to collagen types I, II and III. Stromelysins are represented by MMP-3 and MMP-10 or stromelysin- 1 and -2, respectively; they have specificity for laminin, fibronectin, elastin, gelatin and proteoglycans (MMP-11 is called stromelysin-3 but it is usually grouped with "other MMPs"). Matrilysins are represented by MMP-7 and MMP-26 or matrilysin-1 and -2, respectively; they have specificity for collagen IV, fibronectin, elastin and gelatin. The MT-MMPs are MT1, 2, 3, 4, 5 and 6 - MMP or MMP-14, -15, -16, -17, -24 , and -25 , respectively; they have specificity for collagen, gelatin, fibronectin and laminin $[16,19,27,35,36]$. Finally, the group of gelatinases includes MMP-2 and MMP-9 or gelatinases $\mathrm{A}$ and $\mathrm{B}$, respectively. Gelatinases have a fibronectin domain into the catalytic site, which improves the degradation of denatured collagen (gelatin), type IV (basement membrane) collagen, type V collagen, fibronectin, plasminogen and elastin. The MMP-2, unlike MMP-9, digests type I, II, and III collagens $[16,19,28,35]$.

There are a variety of cells expressing gelatinases. Typically, MMP-2 is produced by macrophages, T-cells, osteoblasts, endothelial and epithelial cells, fibroblasts, keratinocytes and chondrocytes. On the other hand, MMP-9 expression occurs in T-cells, neutrophils, leukocytes, endothelial and breast epithelial cells, osteoclasts, keratinocytes, monocytes, macrophages, and in connective tissue cells $[19,23,30,37]$. Furthermore, and despite their usual extracellular activity, several MMPs have been demonstrated as active proteases localized in nuclei of various human and animal cell types, including heart myocytes, brain neurons, breast and endothelial cells, fibroblasts and hepatocytes [26].

The degradation of ECM by MMPs essentially consists in the disruption and remodeling of structural barriers that enable the occurrence of extravascular tissue access and cellular invasion into the surrounding tissue stroma $[22,23,38]$. However, that process is more complex as it makes the ECM a major influence of cell behavior survival and communication, since it responds to signaling molecules and acts as ligand for cellular adhesion receptors [24,27,28]. Therefore, as MMPs alter and structurally organize ECM, thus altering matrix-derived signals, they are essential to sustain homeostasis, regulating several cellular processes that require ECM breakdown and modification, such as cell shape, movement, growth, differentiation, survival and apoptosis $[16,19,28,34]$.

Generally, both MMP-2 and -9 participate in these processes, where MMP-2 has major roles reducing cell adhesion, stimulating cell migration and differentiation and acting as antiinflammatory factor; the MMP-9, on the other hand, may act as anti- or pro-inflammatory factor [35]. The gelatinases are also linked to the cell spreading and cytoskeletal changes during cell migration [19]. Moreover, MMPs substrates are not limited to ECM proteins; in fact they have the ability to cleave and activate one another, disrupt cell-cell contacts and cleave latent growth factors, proteinases and their inhibitors, blood clotting factors, cell surface receptors, adhesion molecules and intracellular substrates [19,24,28,34,39]. Therefore, MMPs, including gelatinases, are associated with many normal physiological events, such as embryonic development, 
reproduction, ovulation, wound healing, bone resorption, tissue morphogenesis, nerve growth and mammary gland development $[16,23,30,34,38]$.

Usually, alternating cycles of proteolysis and its inhibition prevent an excessive proteolytic activity and tissue destruction [19]. Therefore, in most tissues, basal MMP production is normally very low $[23,28,39]$. The MMP-2, in particular, is widely distributed and is constitutively expressed by most cells with only modest up or downregulation under various conditions [19,29]; on the other hand, MMP-9 expression is normally induced and, while almost MMPs are constitutively secreted after their translation [29,30], MMP-9 can be packaged in neutrophils, being released during specific stimulation [19,23,26,30]. Nevertheless, endothelial cells can release both MMP-2 and -9 very quickly, indicating that they might originate from intracellular storage compartments [26].

At the transcription level, the expression of MMPs can be activated by cytokines and growth factors, including transforming growth factor- $\alpha$ and $-\beta$ (TGF- $\alpha$ and $\beta$, respectively), tumour necrosis factor- $\alpha$ (TNF- $\alpha$ ) interleukins (ILs), interferons, endothelial growth factor (EGF), basic fibroblast growth factor (bFGF), keratinocyte growth factor (KGF), nerve growth factor (NGF) and vascular endothelial growth factor (VEGF), among others [17,18,23,24,28]. In addition to soluble proteins, cell-matrix and cell-cell interactions, mediated by cell-adhesion molecules like epithelial (E)-cadherin and several integrins [21], can also stimulate the expression of MMPs [23]. At the post-transcriptional level, gene expression can be regulated through the stability of mRNA in the cytoplasm [30]. On the other hand, the expression of MMPs can be downregulated by targeting of extracellular components, intracellular growth factors, signal transduction pathways and suppressive factors, which include transforming growth factor-beta (TGF- $\beta$ ), retinoic acids and glucocorticoids [19,23,24,26].

Gelatinases are secreted into the ECM in an inactive or latent form, being called proenzymes or zymogens; the proenzyme secretion, activation and the inactivation of their activities by endogenous inhibitors represent additional regulation processes of these enzymes $[18,19,23,30]$. Initially, each MMP contains an amino-terminal (N-terminal) domain, called predomain, a signal sequence that guides the enzyme for synthesis and secretion in the extracellular environment in a zymogenic form; when that occurs, the pre-domain is lost and the latency of these enzymes is maintained by the cysteine in the pro-domain of the propeptide, which chelates the zinc ion bounded in the active site, formatting a bridge. This interaction can be further abolished by mechanical disruption or other processes (cysteine switch) leading to an intermediate activation, which is followed and completed by the activity of other extracellular proteases, including other MMPs, or even by autocatalytic cleavage; at the time of enzyme activation, the pro-domain is removed [16,23,35,38].

In both humans and dogs, pro-MMP-2 has $72 \mathrm{kDa}$ and may be converted to the 62 or $66 \mathrm{kDa}$ active forms by several enzymes, such as MMP-1,MMP -7, MMP-14, MMP-15, MMP-16, MMP-24, MMP-25, thrombin and plasmin; on the other hand, MMP-2 can activate MMP-1, MMP-13 and MMP-9. In addition to MMP-2, pro-MMP-9 (92 kDa) can be activated to the 82, 84 or $88 \mathrm{kDa}$ active form by MMP-3, MMP-7, MMP-10, MMP-13, MMP-26 and plasmin $[19,28,29,35]$. In the particular case of MMP-9, the substrate binding to proenzime seems to be enough to trigger the cysteine switch. This may explain the fact that usually, the active MMP-9 
is often absent in the tissues, despite the observation of its catalytic activity [19]. Furthermore, MMP-9 exists in plasma as a monomer, complexed as a dimer with a protein named lipocalin, present in activated neutrophils; the MMP-2, on the other hand, is strictly monomeric [19].

Moreover, except for matrilysin, all MMPs also have a hemopexin domain, which is a hemebinding peptide at the carboxyl-terminal (C-terminal) $[16,23,27,29]$. This additional domain is important in substrate recognition and in inhibitor binding [16,27]. The MMPs activity can be inhibited by zinc- and calcium-chelating agents and by specific naturally occurring tissue inhibitors of metalloproteinases (TIMPs), which augment cell adhesion and stabilize cell-cell contacts by inhibiting ECM degradation $[16,19,23,26]$. The TIMPs are secreted proteins, but may be found at the cell surface in most tissues and body fluids, in association with membranebound proteins; based on structure, four different types of TIMPs have been characterized: TIMP-1, $-2,-3$ and $-4[16,28,30,34]$.

Both TIMP-1 and TIMP-2 inhibits MMP-9, although TIMP-1 is more effective; on the other hand TIMP-2 inhibits proMMP-2 over 10-fold more effectively than TIMP-1. However, TIMP-2 has a bi-functional effect on MMP-2, inhibiting its activity in high concentrations, but regulating its activation when present in low levels, by associating to MT1-MMP and pro-MMP-2 at cell surface [28,30,34,38,39]. Like TIMP-1 and TIMP-2, TIMP-3 and TIMP-4 also may inhibit MMP-2 and -9; TIMP-4, particularly can also regulate MMP-2 by inhibiting its activator MT1MMPs [30,34]. In addition, gelatinases, unlike other families, can be regulated by TIMPs before being activated, since these inhibitors can reversibly bind to MMP-2 and -9 zymogens [34,37]. Like MMPs, TIMPs also exhibit biological functions, including mitogenic activities on a number of cell types, which are independent of their MMP-inhibitory activities; therefore, TIMPs are also important regulators in cellular activities [34,38].

Another pos-translation regulation mechanism of MMPs activity is associated with their localization, where specific events concentrate proteinases in the pericellular microenvironment, within the vicinity of their targets $[18,26,28,34]$. These localization mechanisms also limit the access of TIMPs and the extent of proteolysis to discrete regions $[19,26,28]$.

However, as a result of specific protein, genetic and/or epigenetic mutations [23,27-30], and reactive oxygen species influence [18], the functions of MMPs that are essential in normal conditions may develop into pathogenesis. When the regulatory mechanisms are compromised, MMPs production and activity may be abnormally diminished or increased, leading to an improperly ECM degradation [16,23,34,40,41]. Therefore, the occurrence of MMPs deregulation, particularly an increased gelatinase activity $[16,19,34,39]$, is frequently associated with several human and canine pathological events, including: rheumatoid arthritis, inflammatory disorders of the gastrointestinal tract, cerebrovascular, cardiovascular, skin and lung diseases, and cancer $[16,18,19,24,27,29,32]$.

\subsection{Matrix metalloproteinases and cancer}

The MMPs have been implicated in cancer for more than 40 years [18], being overexpressed in a wide range of malignant tumours in response to oncogenic cellular transformation [23,26], cytokines and several growth and angiogenic factors [16,19,23,26,42]. In addition, the com- 
plexity of the tumour microenvironment triggers a variety of regulatory cascades that determine the expression and function of several proteins; therefore, the tumour context is important, that is weather TIMPs and/or activating enzymes in the microenvironment are present or not [18].

Despite they are often produced by invasive cancer cells, most MMPs, under stimulation of ILs and growth factors, are produced by non-malignant stromal cells such as fibroblasts, endothelial cells and bone marrow-derived cells, including macrophages [5,17,19,21,43]. Furthermore, MMPs are typically required in the early stage of the tumour progression $[19,20]$ due to their ability to degrade the ECM, basement membranes, growth-factor receptors, cytokines, chemokines, cell adhesion molecules, apoptotic ligands and angiogenic factors [17, $27,33]$, since that contributes to tumour proliferation, invasion, intravasation into circulation, extravasation, migration to metastatic sites and angiogenesis $[16,19,21,26,27]$. Therefore, several proteins, including MMPs, integrins, matrix proteins are gathered when the cells need to invade and migrate and come across a non-degraded ECM [19].

On the other hand, MMPs may deregulate the balance between growth and antigrowth signals in the tumour microenvironment $[18,20,44]$. Additionally, MMPs orchestrate inflammation, which is linked to cancer progression $[18,19,43]$, and are also associated with mechanisms that cancer cells develop to avoid host immune response, mainly through the suppression of Tlymphocytes proliferation or by decreasing the tumour cells sensitivity to natural killer (NK) cells $[19,23,25,26,31]$. The MMP function is also involved with the ability of malignant cells to evade apoptosis, by cleaving ligands and receptors that transduce pro-apoptotic signals $[18,23,24]$. Furthermore, the overexpression of MMPs, gelatinases in particular, can also cause EMT and induce genomic instability $[17,18]$. Consequently, the presence of MMPs in malignant diseases, including gelatinases, is often correlated with highly aggressive tumours and low prognosis, both in humans and dogs $[18,27,32,43,45]$.

However, the degradation of ECM components and other extracellular molecules, although under malignant stimulation, may generate fragments with new bioactivities that inhibit angiogenesis [18]. On the other hand, TIMPs expression in tumour tissue and stroma generally inhibits tumour cell growth, reduces the invasive and metastatic capacity of tumour cells and prevents angiogenesis $[16,34,42,46,47]$. Hence, it would be logical to assume that during cancer development, an high MMP:TIMP ratio would be present [44]. However, an excessive activity of MMPs may difficult tumour cell adhesion by destroying cell-matrix interactions or matrix signals required for cell migration, invasion and angiogenesis; therefore, even in cancer progression, a certain balance between MMPs and TIMPs is needed, in order to allow the remodeling of stromal tissues [19,20,26,44].

Among all MMPs, the gelatinases and respective proenzymes are two of the most important members in the development and invasion of tumour cells in several neoplasias. Both MMP-2 and MMP-9 are expressed in a variety of human $[16,19,25,27,43,48]$ and canine $[32,33,45,49-52]$ cancers, including lymphoma, glioma, ovarian, lung, bladder, pancreatic, prostate, renal, oral, gastric, and breast cancers, neuroblastoma, promyelotic leukemia, fibrosarcoma, osteosarcoma, cutaneous mast cell tumours and melanoma. 
With respect to balance deregulation between growth and anti-growth signals, as MMPs substrates, latent growth factors can be activated by gelatinases [20]. For instance, they are able to release the active TGF- $\beta$, thus promoting angiogenesis and tumour metastasis $[4,17-19,44]$; on the other hand, TGF- $\beta$ up-regulates the MMP-2, acting as a strong autocrine mediator of tumour cell invasion [4]. Moreover, neutrophil-derived pro-MMP-9 is not complexed with TIMP-1, being more readily activated to drive tumour angiogenesis by activating the basic fibroblast growth factor 2 (FGF-2) pathway [17,18]. Likewise, MMP-9 is implicated in vasculogenesis and regulates the bioavailability of bFGF and VEGF, the most potent inducer of tumour angiogenesis, which may also affect lymphangiogenesis [17-19,43,45]. The increased expression of MMP-2 is also associated with lymphatic invasion and lymph node metastases [18].

Additionally, not only the presence of MMPs, but also their cellular location plays a crucial role in cell invasion [53]; during invasion, the localization of MMPs to specialized cell surface structures is requisite for their ability to promote invasion [17]. Thus, the cell surface-bound gelatinases also play a role in cancer progress; in leukemic cells, for example, pro-MMP-9 interacts with intercellular adhesion molecule-1 (ICAM-1), enhancing tumour cell resistance to NK cell-mediated cytotoxicity $[19,25,26]$. Furthermore, the gelatinases cell surface activity has been found to be dependent of cell adhesion molecules, such as integrins, for tumour migration, invasion angiogenesis in many cancers $[5,10,19,23,26,28]$.

In human melanoma cells, particularly, MMP-2 and -9 have been focus of attention in the last years, both in cutaneous [4,5,27,43,48,53-57], as well as in eye [11,58-62] and oral melanoma [6]. Although the role of MMPs in melanoma remains controversial [5,55], both gelatinases are often overexpressed in melanocytic tumours, frequently in advanced stages of melanoma, thus being associated to the most invasive and aggressive cases and to a low prognosis and patient outcome. The specific activation processes and the localization of MMPs during migration of melanoma cells is still poorly understood [5]; nevertheless, MMP-2 and -9 have been detected in a high number of vesicular organelles, which may be a way of achieving a rapid and directional proteolysis during cell migration, invasion and angiogenesis [26]. In veterinary medicine, as the best authors' knowledge only two studies concerning the gelatinases expression have been made in canine melanocytic tumours, one in cutaneous lesions [49] and the other in oral melanomas [51].

Conversely to the majority of the observations, there are several MMPs, including gelatinases, with the ability to negatively control some aspects of cancer progression. Particularly, MMP-2 and -9 are able to cleave plasminogen, which creates angiostatin, and MMP-9 can also cleave a basement membrane collagen type XVIII, creating a product named endostatin; both cleavage products can inhibit endothelial cell proliferation and angiogenesis [20,22,27,38,44]. Similarly a few studies indicate a positive correlation between increased TIMP levels and poor outcome in some human malignancies [40]. Although the significance of this event remains unclear, it seems that the role of each MMP and TIMP depends on the type of cell that produces the enzyme (tumour cell or stroma), the cancer stage, the tumour site (primary or metastasis), the substrate profile, the tissue of neovascularization and several microenvironmental factors [17-20]; however, the significance of this event remains unclear [20,27,44]. 
In the context of cancer therapy, several clinical trials have been developed in both humans and dogs, in order to inhibit MMP activity [18,32,52], particularly the activity of gelatinases, in several malignant diseases, including melanoma $[27,42]$. The majority of these studies are based on the use of TIMPs or synthetic inhibitors [20,26,27,42] and knockout experiments [19, 42], where MMP-2 and MMP-9 are absent. In addition, similar studies are based on the degradation of particular cell receptors that bind to gelatinases [19]. Although some these inhibition studies remain controversial, promising results have been observed, including the reduction of the growth and invasion of the more aggressive cases [19-21,26,27]. The presence of anti-tumour MMPs may be the underlying cause of lack of success of some of these clinical trials [27]; therefore, the dual role of MMPs in angiogenesis highlights the need to develop selective MMP inhibitors [20].

On the bases of what was previously described, MMPs are undeniably important factors influencing tumour behavior; however, there is still not enough knowledge about the function of individual MMPs in cancer [19,27]. As the dog has been considered a good model for studies of spontaneous melanoma [8,13-15] and since the role of MMPs in canine melanocytic tumours is still poorly explored and understood, the aims of the present work are to study the immunoexpression of MMP-2 and MMP-9 in canine cutaneous melanocytic tumours and the association between them and several pathological characteristics.

\section{Material and methods}

\subsection{Tissue processing and tumour classification}

From the archive of the Histopathology Laboratory of the University of Trás-os-Montes and Alto Douro, 42 canine cutaneous melanocytic tumours and 5 normal skin samples were obtained. These tumours were excised from dogs presented for treatment at the Veterinary Teaching Hospital of the University of Trás-os-Montes and Alto Douro and several other veterinary private clinics. The anonymity of the sample sources was respected.

The samples were fixed in $10 \%$ buffered formalin and paraffin embedded. For the histopathologic study, 4- $\mu$ m-thick tissue sections were stained with hematoxylin and eosin, with and without melanin blanching, depending on the amount of pigment. The blanching was performed by slide incubation in $0,25 \%$ potassium permanganate for $30-60$ minutes and 0,1\% oxalic acid for 5-8 minutes. Each sample was re-examined by two independent pathologists (IP and JP) in order to confirm the diagnosis, according to the World Health Organization International Histological Classification of Tumours of Domestic Animals criteria [63]. All slides were taken into consideration for this study and complete sections of the tumours were fully analysed.

\subsection{Histopathological evaluation}

The following pathological features were evaluated: histological type - melanocytoma (benign), melanoma (malign); presence of ulceration; presence of necrosis; mitotic index; 
nuclear grade; degree of pigmentation, presence of aberrant tumoural cells; stroma; and tumoural vascular invasion. Mitotic index was calculated by counting all the mitosis present in 10 high power fields (HPF) (400x): mitotic index I ( $<3$ mitosis in $10 \mathrm{HPF}$ ); mitotic index II (3-5 mitosis in $10 \mathrm{HPF}$ ) or mitotic index III ( $>5$ mitosis in $10 \mathrm{HPF})$. For nuclear grade, the following grades were defined: nuclear grade I when the nuclei had minimal variations in their shape and size compared to normal nuclei; nuclear grade II consisted of moderate alterations of nuclear shape; and nuclear grade III consisted of the nuclei that were irregular and larger than normal [64].The degree of pigmentation was estimated using a subjective scale from scant (pigment in fewer than $30 \%$ of cells), moderate (pigmentation in $31-80 \%$ of cells), and abundant (pigment in more than $80 \%$ of cells). The amount of stroma was categorized in: scant, moderate, and abundant [65].

\subsection{Immunohistochemistry}

For immunohistochemical studies, 3- $\mu$ m sections were cut from each specimen and mounted on silane-coated slides. MMP-2 and MMP-9 immunoexpression were carried out by the streptavidin-biotin-peroxidase complex method, with a commercial detection system (Ultra Vision Detection System; Lab Vision Corporation) following the manufacturer's instructions, with and without blanching. All the washes and dilutions were made in phosphate buffered saline (PBS) solution ( $\mathrm{pH}=7.4)$.

Sections were deparaffinized in xylene and rehydrated in a graded alcohol series, ending in tap water. The blanching was performed with $0,25 \%$ potassium permanganate $\left(\mathrm{KMnO}_{4}\right)$ and $0,1 \%$ oxalic acid $\left(\mathrm{H}_{2} \mathrm{C}_{2} \mathrm{O}_{4}\right)$. For MMP-2, antigens were retrieved by microwave treatment for $20 \mathrm{~min}$ at $750 \mathrm{~W}$ in a solution of citrate buffer, in distilled water. No pre-treatment was used for MMP-9 labeling.

After cooling the slides at room temperature, endogenous peroxidase was blocked, through the incubation with 3\% hydrogen peroxidase for 30min. Slides were then dried and sections outlined with a hydrophobic pen (Liquid Blocker, Daido), washed in PBS for $5 \mathrm{~min}$ and applied the blocking serum for $5 \mathrm{~min}$ (Ultra VBlock, Labvision Corporation). Subsequently the sections were incubated overnight at $4 \circ \mathrm{C}$, with the primary antibodies: MMP-2 (Neomarkers) diluted 1:150 and MMP-9 diluted 1:200 (Neomarkers) in phosphate buffered saline (PBS; pH 7,4; 0,01 $\mathrm{M})$. On the following day, sections were washed in PBS for $5 \mathrm{~min}$, at room temperature, and then applied biotinylated serum and streptavidine peroxidase for 10min each (both included in the kit Ultravision Detection System, Labvision Corporation), with intermediate washings in PBS, for 5min. Immunolabeling was observed by incubation with 3,3-diaminobenzidine tetrahydrochloride (DAB; SIGMA) 0,05\% with $0,01 \% \mathrm{H}_{2} \mathrm{O}_{2}$ for $5 \mathrm{~min}$. After washing in distilled water, the sections were counterstained with Gill haematoxylin, dehydrated, cleared and mounted. Each set of staining included a known positive control. The primary antibody was replaced by PBS and by an irrelevant antibody for negative controls 


\subsection{Immunohistochemistry evaluation}

Positivity was indicated by the presence of distinct brown cytoplasmic labeling. Each specimen was evaluated in a blinded manner by 2 independent investigators (IP e FLQ). The interobserver variability was low; in case of discrepancy, a consensus was reached among 3 observers. The number of malignant cells expressing MMP-2 and MMP-9 was assessed using a semiquantitative scale by estimating the percentage of positive tumoural cells (labeling extension). A 4-grade scale was used: negative, $0,<5 \% ; 1,5-20 \%$ of positive cells; $2,21-49 \%$; and 3 , over $50 \%$ of positive cells (adapted from [57]). The labeling intensity was recorded as: negative (0); weak $(+)$; moderate $(++)$ and strong $(+++)$.

\subsection{Statistical analysis}

Statistical analyses were made to determine correlation between MMPs immunoexpression (labeling extension and intensity) and tumor diagnosis (benign or malignant), and between MMPs immunoexpression in malignant melanomas and the pathological variables under study. The statistical software SPSS (Statistical Package for Social Sciences, IL, USA), version 12.0, was used for statistical analysis. We performed a chi-square test $\left(\chi^{2}\right)$ for studying categorical variables. In all statistical comparisons, $\mathrm{p}<0.05$ was accepted as denoting significant differences.

\section{Results}

\subsection{Tumours}

The studied canine cutaneous melanocytic tumours were originated from dogs of different breeds. Undefined breed ( $n=13 / 42)$, Boxer $(n=11 / 42)$, Rottweiller $(n=5)$ and Cocker Spaniel $(n=2)$ were most commonly represented. The age of the animals ranged from 9 months to 15 years, with an average of 10 years. Twenty dogs were female and 22 were male.

The lesions occur as nodules solitaries, occasionally ulcerated, varying in size between 0,4-9 $\mathrm{cm}$ (average of $2,7 \mathrm{~cm})$.

From the 42 tumours included in the study, 11 cases were classified as melanocytomas (benign tumours) and 21 cases as malignant melanomas.

\subsection{MMP-2 and MMP-9 expression in canine cutaneous melanocytic tumours}

Five samples of normal skin and 42 melanocytic tumours were examined (Table 1). Occasional dermal fibroblasts and macrophages were positive for both MMP-2 and MMP-9 in normal skin and tumours.

Intracytoplasmic immunostaining for MMP-2 and MMP-9 immunoreactive protein was found in epidermal and dermal nests of tumoural cells, both centrally and peripherally. Positive cells were homogeneously distributed without any constant increase in invasive fronts. 


\begin{tabular}{|c|c|c|c|c|c|}
\hline \multirow{2}{*}{ Sample $n^{\circ}$} & \multirow{2}{*}{$\begin{array}{l}\text { Histological } \\
\text { Classification }\end{array}$} & \multicolumn{2}{|c|}{ MMP-2 } & \multicolumn{2}{|c|}{ MMP-9 } \\
\hline & & Extension & Intensity & Extension & Intensity \\
\hline 1 & Melanoma & 3 & +++ & 1 & + \\
\hline 2 & Melanocytoma & 3 & ++ & 2 & ++ \\
\hline 3 & Melanocytoma & 2 & +++ & 0 & 0 \\
\hline 4 & Melanoma & 3 & +++ & 1 & + \\
\hline 5 & Melanocytoma & 3 & +++ & 3 & + \\
\hline 6 & Melanocytoma & 3 & ++ & 0 & 0 \\
\hline 7 & Melanoma & 2 & + & 2 & ++ \\
\hline 8 & Melanoma & 1 & ++ & 1 & + \\
\hline 9 & Melanoma & 1 & ++ & 2 & ++ \\
\hline 10 & Melanoma & 3 & + & 3 & +++ \\
\hline 11 & Melanoma & 2 & + & 3 & + \\
\hline 12 & Melanoma & 2 & + & 3 & +++ \\
\hline 13 & Melanoma & 3 & ++ & 2 & ++ \\
\hline 14 & Melanoma & 1 & + & 3 & ++ \\
\hline 15 & Melanoma & 1 & + & 3 & ++ \\
\hline 16 & Melanocytoma & 3 & ++ & 0 & 0 \\
\hline 17 & Melanocytoma & 3 & ++ & 3 & + \\
\hline 18 & Melanoma & 1 & + & 3 & +++ \\
\hline 19 & Melanoma & 2 & ++ & 2 & ++ \\
\hline 20 & Melanoma & 3 & + & 3 & ++ \\
\hline 21 & Melanoma & 2 & + & 1 & +++ \\
\hline 22 & Melanocytoma & 3 & ++ & 0 & 0 \\
\hline 23 & Melanocytoma & 3 & ++ & 2 & + \\
\hline 24 & Melanocytoma & 3 & ++ & 2 & + \\
\hline
\end{tabular}




\begin{tabular}{|c|c|c|c|c|c|}
\hline \multirow{2}{*}{ Sample $n^{\circ}$} & \multirow{2}{*}{$\begin{array}{l}\text { Histological } \\
\text { Classification }\end{array}$} & \multicolumn{2}{|c|}{ MMP-2 } & \multicolumn{2}{|c|}{ MMP-9 } \\
\hline & & Extension & Intensity & Extension & Intensity \\
\hline 25 & Melanoma & 1 & ++ & 2 & ++ \\
\hline 26 & Melanoma & 3 & ++ & 2 & ++ \\
\hline 27 & Melanoma & 2 & ++ & 1 & + \\
\hline 28 & Melanocytoma & 3 & +++ & 2 & + \\
\hline 29 & Melanocytoma & 3 & +++ & 2 & + \\
\hline 30 & Melanoma & 2 & ++ & 1 & + \\
\hline 31 & Melanoma & 1 & + & 1 & + \\
\hline 32 & Melanoma & 3 & + & 3 & +++ \\
\hline 33 & Melanoma & 1 & + & 1 & ++ \\
\hline 34 & Melanoma & 2 & + & 1 & + \\
\hline 35 & Melanoma & 2 & + & 3 & ++ \\
\hline 36 & Melanoma & 1 & + & 3 & + \\
\hline 37 & Melanoma & 1 & ++ & 3 & ++ \\
\hline 38 & Melanoma & 2 & + & 1 & ++ \\
\hline 39 & Melanoma & 3 & ++ & 3 & +++ \\
\hline 40 & Melanoma & 3 & ++ & 3 & ++ \\
\hline 41 & Melanoma & 3 & + & 3 & + \\
\hline 42 & Melanoma & 2 & + & 1 & + \\
\hline
\end{tabular}

Extension $-<5(0), 5-20 \%(1), 21-50 \%(2),>51 \%$ of positive cells (3); Intensity - negative (0), weak (+), moderate (++), strong $(+++)$

Table 1. MMP-2 and MMP-9 immunoexpression in canine cutaneous melanocytic tumours.

The expression of MMP-2 was observed in all tumours. The percentage of labeled cells ranged from ( 1 ) isolated cells ( $n=10 ; 23.8 \%)$, to ( 2 ) foci of labeled cells $(n=12 ; 28,6 \%)$, to (3) diffuse labeled cells ( $n=20 ; 47,6 \%)$. With respect to labeling intensity, there was weak positivity $(+)$ in 18 cases $(42,9 \%)$, moderate intensity (++) of labeling in 18 cases $(42.9 \%)$ and strong intensity (+++) in 6 cases $(14,3 \%)$, which is represented in Figures 1 and 2. 


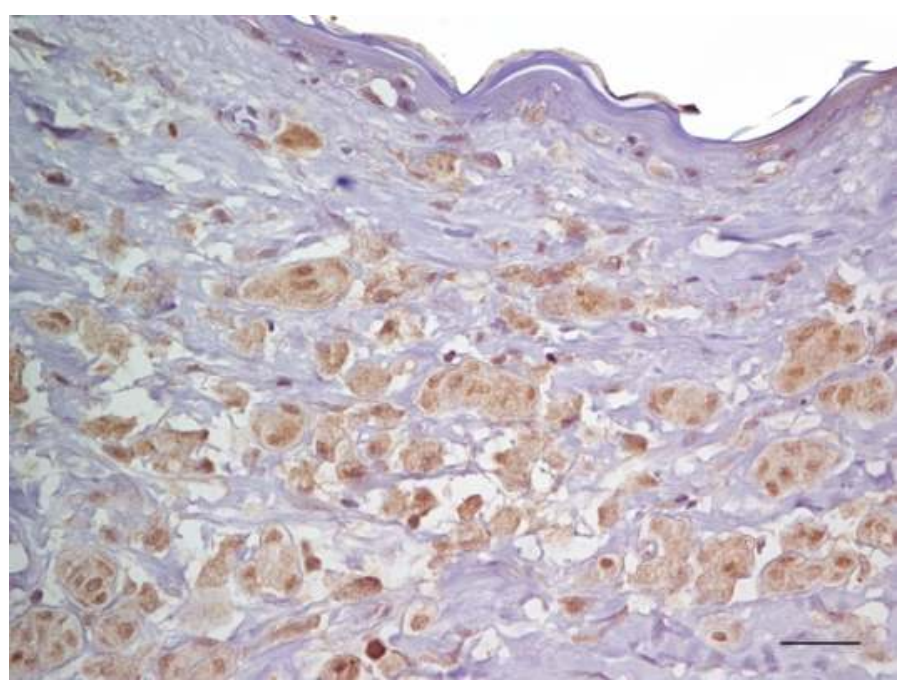

Figure 1. MMP-2 expression in canine cutaneous melanocytoma: difuse (3) and moderate labelling intensity (++). IHC. Bar, $30 \mu \mathrm{m}$

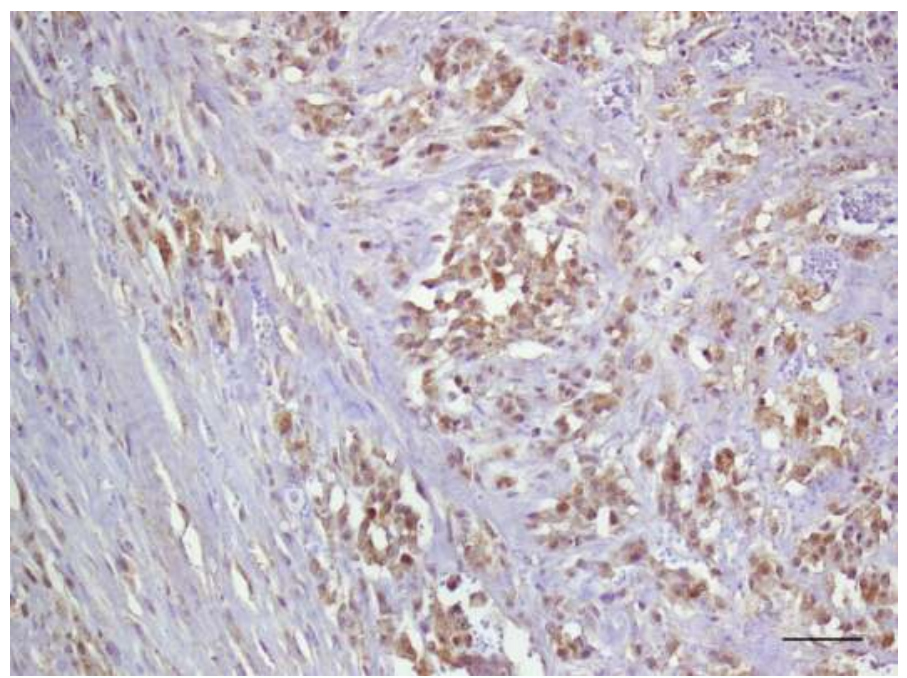

Figure 2. MMP-2 expression in canine cutaneous malignant melanoma. The positivity is moderate in a 2 extension of positive cells IHC. Bar, $60 \mu \mathrm{m}$

For MMP-9 immunolabeling extension, 16 melanocytic tumours showed a diffuse (3) immunolabeling (36.1\%), and 22 an intermediate labeling (2) pattern represented in Figure 3. Only 4 tumours were negative $(9,5 \%)$. For labeling intensity, the weak $(+)$ and moderate $(++)$ labeling 
pattern (Figure 3) was most frequently observed ( $\mathrm{n}=17$ and $\mathrm{n}=15$ respectively). Six cases showed a strong $(+++)$ reaction to MMP-9 (Figure 4).

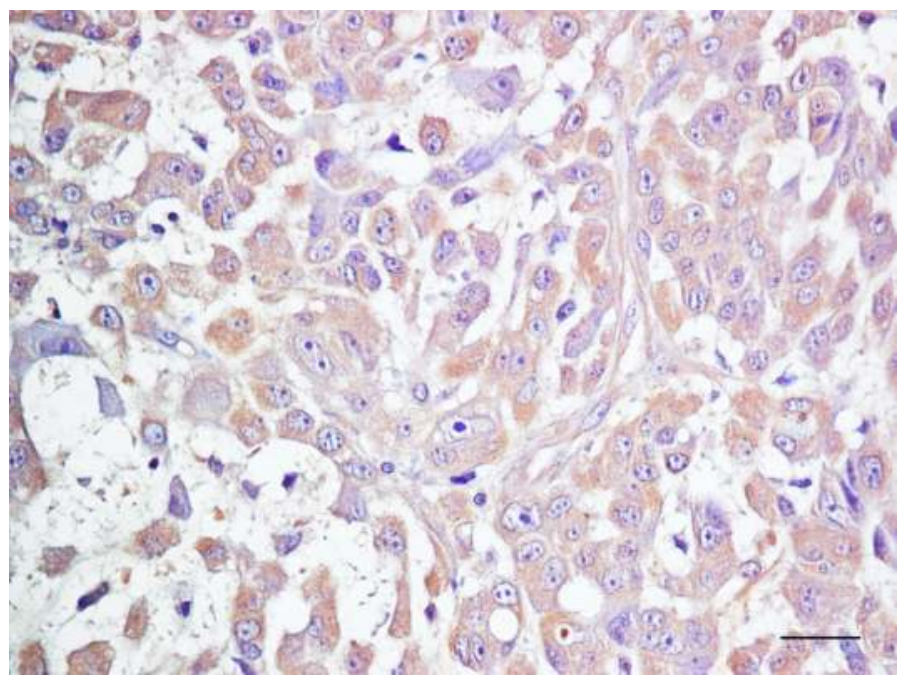

Figure 3. Difuse (3) MMP-9 expression in canine malignant melanoma, with a moderate intensity (++). IHC. Bar, $30 \mu \mathrm{m}$

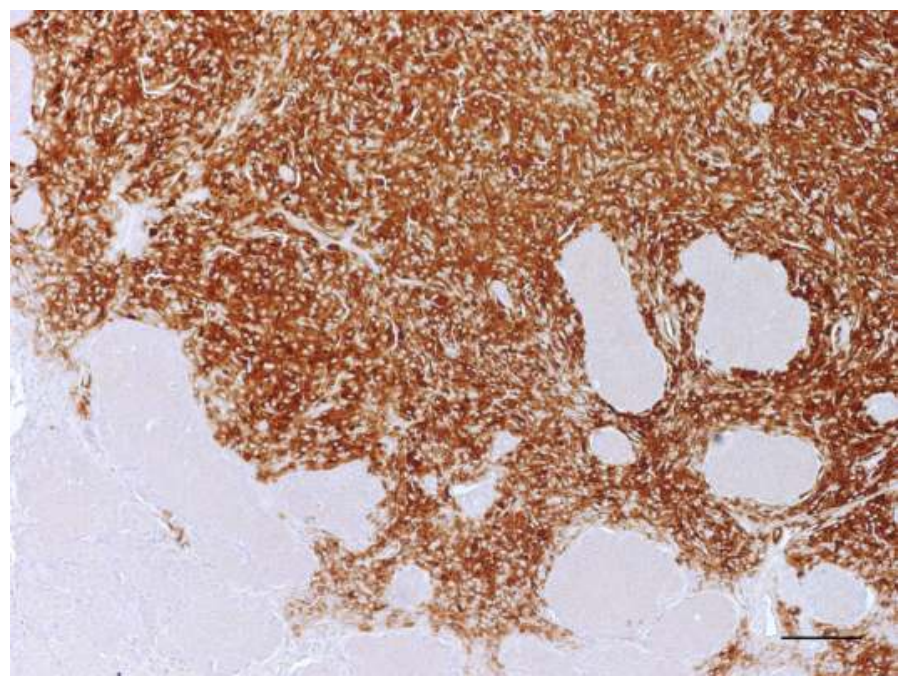

Figure 4. MMP-9 expression in canine malignant melanoma, with a difuse (3) and strong (+++) labelling intensity. The tumoural cells invades hepatoid perianal gland. IHC. Bar, $120 \mu \mathrm{m}$ 


\subsection{Association between MMP-2 and MMP-9 expression and tumour malignancy}

The percentage of MMP-2 positive cells and the intensity of reaction were significantly different between benign and malignant tumours. Benign tumours (melanocytomas) showed a higher expression of MMP-2 [both for extension $(p=0,003)$ and intensity $(p=0,02)$ ] than malignant melanomas (Table 2).

Regarding MMP-9, the differences observed between benign and malignant tumours were statistically significant both for the extension of positive cells $(p<0,0001)$ and for the labeling intensity $(p=0,001)$. Malignant melanomas generally showed a higher number of positive cells than benign tumours The melanocytomas did not show MMP-9 or, when present, the immunoexpression was generally weak (Table 2).

\begin{tabular}{|c|c|c|c|c|c|c|c|c|}
\hline & & \multicolumn{2}{|c|}{ Melanocytoma } & \multicolumn{2}{|c|}{ Melanoma } & \multicolumn{2}{|c|}{ Total } & \multirow{2}{*}{$p$} \\
\hline & & $\mathbf{n}$ & $\%$ & $\mathrm{n}$ & $\%$ & $\mathrm{n}$ & $\%$ & \\
\hline \multicolumn{9}{|l|}{ MMP-2 } \\
\hline \multirow{3}{*}{ Extension } & 1 & 0 & $0 \%$ & 10 & $40,7 \%$ & 10 & $23,8 \%$ & \multirow{3}{*}{0,003} \\
\hline & 2 & 1 & $9,1 \%$ & 11 & $40,7 \%$ & 12 & $28,6 \%$ & \\
\hline & 3 & 10 & $90,9 \%$ & 10 & $18,6 \%$ & 20 & $47,6 \%$ & \\
\hline \multirow{3}{*}{ Intensity } & + & 0 & $0 \%$ & 18 & $58,1 \%$ & 18 & $42,9 \%$ & \multirow{3}{*}{0,002} \\
\hline & ++ & 7 & $63,6 \%$ & 11 & $35,5 \%$ & 18 & $42,9 \%$ & \\
\hline & +++ & 4 & $36,4 \%$ & 2 & $6,5 \%$ & 6 & $16,3 \%$ & \\
\hline \multicolumn{9}{|l|}{ MMP-9 } \\
\hline \multirow{4}{*}{ Extension } & 0 & 4 & $36,4 \%$ & 0 & $0 \%$ & 4 & $9,5 \%$ & \multirow{4}{*}{$<0,0001$} \\
\hline & 1 & 0 & $0 \%$ & 11 & $35,5 \%$ & 11 & $26,2 \%$ & \\
\hline & 2 & 5 & $45,5 \%$ & 6 & $19,4 \%$ & 11 & $26,2 \%$ & \\
\hline & 3 & 2 & $18,2 \%$ & 14 & $45,2 \%$ & 16 & $38,1 \%$ & \\
\hline \multirow{4}{*}{ Intensity } & 0 & 4 & $36,4 \%$ & 0 & $0 \%$ & 4 & $9,5 \%$ & \multirow{4}{*}{0,001} \\
\hline & + & 6 & $54,5 \%$ & 11 & $35,5 \%$ & 17 & $40,5 \%$ & \\
\hline & ++ & 1 & $9,1 \%$ & 14 & $45,2 \%$ & 15 & $35,7 \%$ & \\
\hline & +++ & 0 & $0 \%$ & 6 & $19,4 \%$ & 6 & $14,3 \%$ & \\
\hline
\end{tabular}

Table 2. MMP-2 and MMP-9 immunoexpression in benign and malignant canine cutaneous melanocytic tumours.

\subsection{Association between MMP-2 and MMP-9 and pathological features in canine cutaneous melanoma}

The association analysis between MMP-2 immunoexpression (for labeling extension and intensity) in malignant melanomas $(n=31)$ and the pathological criteria showed that the differences observed in labeling extension and intensity were not associated with any param- 
eter $(p>0,05)$, except for MMP-2 intensity and nuclear grade $(p=0,049)$. Table 3 presents the pathological variables analyzed and their association with MMP-2 expression in canine cutaneous malignant melanomas.



Table 3. Association of pathological variables with MMP-2 expression in canine cutaneous malignant melanomas.

MMP-9 labeling intensity presented a statistical significant association with the presence of necrosis $(p=0,032)$, nuclear grade $(p=0,09)$, and degree of pigmentation $(p=0,008)$. Canine 
melanocytic tumours without necrosis, with a lower nuclear grade and more pigmented, showed a higher MMP-9 labeling intensity. In respect to MMP-9 extension, a positive association is observed with the degree of pigmentation $(p=0,003)$, where the percentage of MMP-9 positive cells is higher in malignant melanomas with abundant amounts of melanin (Table 4).

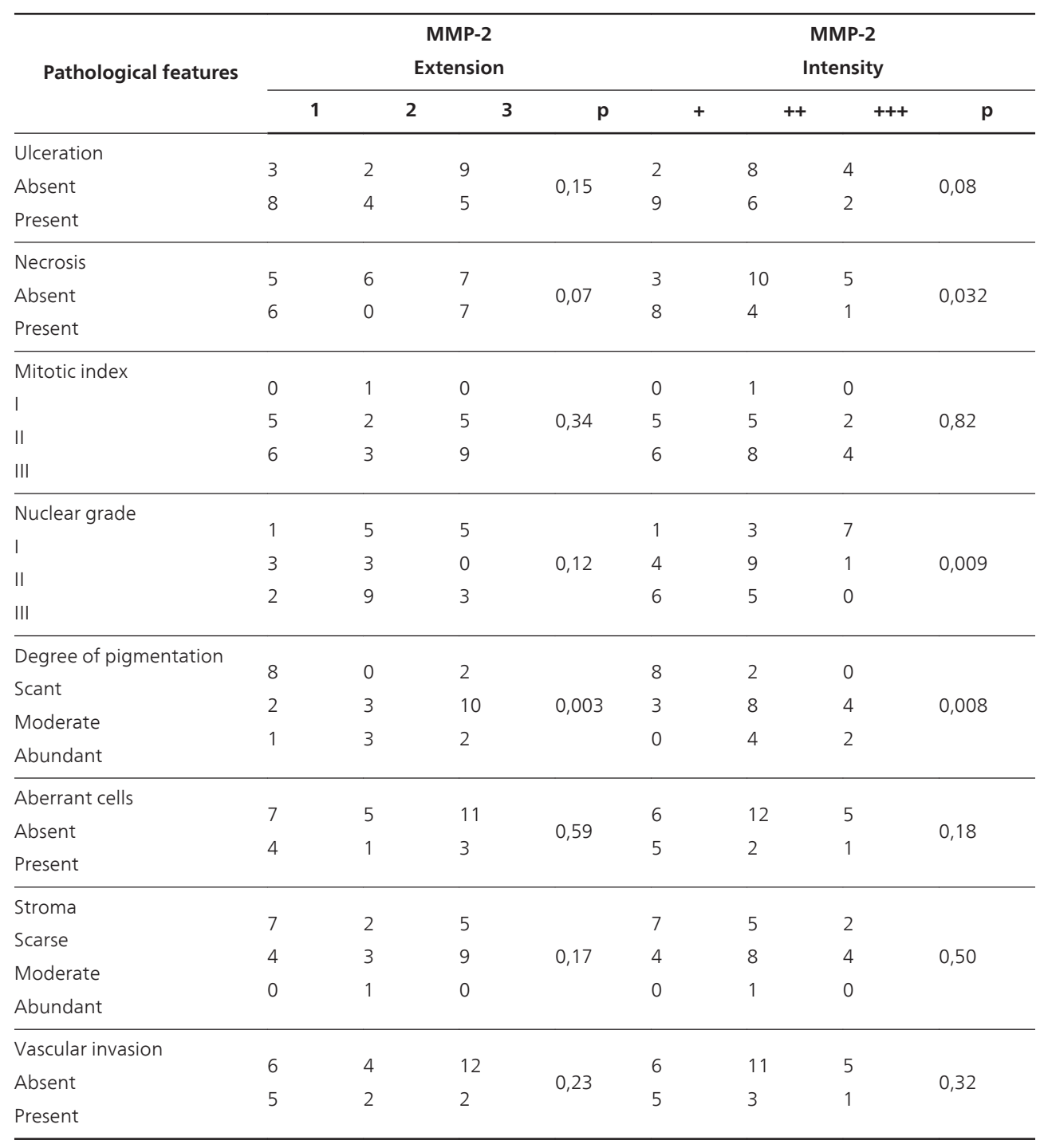

Table 4. Association of pathological variables with MMP-9 expression in canine cutaneous malignant melanomas. 


\section{Discussion}

Cutaneous melanoma is one of the most frequent malignant tumours in younger age people and is characterized by its high capacity for invasion and metastasis. The incidence of human cutaneous melanoma is increasing in the U.S.A., Australia, and Europe [66,67]. Among canine population, the incidence of melanocytic tumours is also increasing. Cutaneous canine melanocytic neoplasms are usually benign. However, when malignant they could be highly aggressive metastasizing both locally as in distant organs [2,68-70].

Human cutaneous melanoma may develop de novo from normal melanocytes or from potential precursor lesions, such as atypical dysplastic nevi or congenital nevi $[66,67]$ but in the dog this evolution is not well established.

Canine malignant melanoma is resistant to most current therapeutic regimens. The search of novel therapeutic tools is crucial in the fight against this disease. Furthermore, the similarities between human and canine melanoma make spontaneous canine melanoma an excellent disease model for studying the corresponding human disease [14,71].

Much work is currently underway in order to identify specific tumour markers, associated with malignancy [71-73]. However, more studies are needed to differentiating benign from malignant canine melanocytic neoplasms or predicting survival times.

The involvement of ECM-degrading enzymes, such as MMPs and serine proteases, during tumour progression and metastasis is well established [28,30]. During the last few decades, in both human and veterinary oncology there has been considerable interest in studying MMPs activity as a possible independent prognostic marker and target for therapeutic options $[19,27,29,31,32]$. However, the biological significance of expression of MMP-2 and MMP-9 expression in melanocytic tumours is still poorly understood, presenting conflicting results regarding the relation of MMP expression and the invasiveness of melanoma cells both in vitro and in vivo [11,74-76].

In canine melanocytic tumours, studies concerning MMP-2 and MMP-9 expression are very scarce $[49,51]$, and as far as we know, only one study was performed in cutaneous melanocytic tumours [49] until present.

Here, we analyzed the expression patterns of MMP-2 and MMP-9 in benign and malignant canine cutaneous melanocytic tumors and its relation with classical parameters of aggressiveness in malignant melanoma.

In our study, both benign and malignant lesions express MMP-2, according to human analogous studies [60]. However, MMP-2 labeling was significantly higher in benign melanocytic tumours than in malignant counterpart, contrarily to a previous human study, in wich MMP-2 expression was higher in malignant lesions [60]. Indeed, in vitro and in vivo studies suggests that MMP-2 activity could be related to the progression of melanoma and may be required for melanoma cell invasion and metastasis formation [59,77-79]. In canine cutaneous melanocytic tumours, Docampo et al. [49] did not observe any differences in MMP-2 expression between benign and malignant neoplasias. 
We also observed that, in canine cutaneous malignant melanoma, a higher intensity of the MMP-2 labeling appears to be associated, in a statistical significant way, with nuclear grade $(\mathrm{p}=0,049)$ but not with other histological features. Interestingly, in dogs, this characteristic seems to be very accurate in predicting overall behavior in these tumours [80]. Being this, MMP-2 could be implied in canine melanoma aggressiveness. These data are in agreement with previous human studies, where the expression of MMP-2 increased notably with architectural disorder, atypia, and progression to melanoma [81,82]. Additionally, some of these studies observed a correlation between MMP-2 expression and human melanoma metastization and prognosis [60,83-86]. Indeed, active MMP-2 regulates VEGF-A in melanoma cells on a transcriptional level via an integrin $\alpha \mathrm{v} \beta 5 /$ phosphoinositide-3-kinase-dependent pathway. In that context, MMP-2 plays a pivotal role in the autocrine regulation of VEGF-A expression in melanoma cells, and consequently in angiogenesis [87]. However, in our study, in spite of the association of MMP-2 and nuclear grade, we observed a lack of a association with vascular tumoural embolus, that needs to be clarified.

With respect to MMP-9, in our samples, all melanomas expressed this MMP, like described in human ciliary body melanomas [88]. We also observed significant differences in MMP-9 labeling extension $(p<0,0001)$ and intensity $(p=0,001)$ between benign and malignant tumours. Malignant tumours had a higher MMP-9 expression as described in a previous study in canine melanocytic tumours [49]. The differences found in MMP-9 immunoreactivity between benign and malignant lesions were also similar to the previously described in human melanocytic neoplasms [89] and lead us to speculate that MMP-9 might be involved in the neoplastic transformation of canine melanocytic tumours. In human benign pigment cell lesions, MMP-9 was expressed in cellular blue nevi whereas all other benign lesions, including common blue nevi, were negative. In malignant melanomas MMP-9 was variably expressed in the pure and invasive radial growth phase but not in the vertical growth phase [90].

Analyzing MMP-9 expression and the pathological parameters, we observed that MMP-9 presented a statistical significant association between its labeling intensity and the presence of necrosis $(\mathrm{p}=0,032)$, nuclear grade $(\mathrm{p}=0,09)$ and degree of pigmentation $(\mathrm{p}=0,008)$. Additionally, MMP-9 extension was significantly associated with the degree of pigmentation $(p=0,003)$. These characteristics are classically linked to higher tumoural aggressiveness and poor clinical prognosis in these neoplasias. However, contrarily to the expected, the less aggressive tumours, without necrosis, with a lower nuclear grade and elevated pigmentation degree, showed a higher MMP-9 labeling. Even non consensual, some previous studies in melanoma suggest the opposite [91-93]. In vitro, MMP-9 expression was present or could be induced only in cell lines derived from advanced primary melanomas, and was absent in cell lines derived from early stage primary lesions [94]. In other study, the authors showed that less aggressive cell lines were unable to produce MMP-9 after treatment with either interleukin-1 $($ IL-1 $\beta$ ) or tumour necrosis factor $\alpha(\mathrm{TNF}-\alpha)$ [93]. In murine, integrin receptor $\alpha 5 \beta 1$ and extracellular matrix fibronectin ligand interaction induce the invasive potential of B16F10 cells and MMP-9 induction is the downstream effectors in the process [95]. 
In skin human melanoma, an involvement of MMP- 9 in invasion and metastatic growth, as in the regulation of tumour growth and progress has been suggested, by modulation of the levels of N-cadherin and PCNA [96]. Also, in human uveal melanomas, MMP-9 was associated with the presence of necrosis, a high mitotic rate [62] and with metastization [11]. In opposition, no correlation was found between MMP-9 immunoreactivity occurrence of metastases in cases of human ocular melanomas [88]. It has been proposed that not the melanoma cells themselves, but the tumour-surrounding host cells secrete MMP-9 in vivo, indicating that host-derived MMP-9 plays an important role in melanoma metastasis formation [97].

In canine cutaneous melanocytic tumours, according to our results, early invasion seems to be associated with de novo expression of MMP-9 by neoplastic melanocytes. The lack of association with aggressiveness in malignant lesions could suggest that other factors are involved in tissue degradation during later stages of tumour progression, as proposed in human melanocytic tumours [90].

Summarizing, in our study, malignancy is associated with an increase of MMP-9 and a decrease of MMP-2 expression. In malignant lesions, however, the aggressiveness, evaluated by nuclear grade, seems to be associated with a decrese of MMP-9 and an increase of MMP-2 expression. These results suggest that might occurs a switch in the MMP expression profile during tumour progression, involving not only emergence of MMP expression but also its downregulation, as described in human melanoma [93].

Nevertheless, further studies involving MMPs, their tissue inhibitors, and other regulation factors and their correlation with prognostic are needed to clarify this subject in canine melanocytic tumours.

\section{Conclusion}

Both MMP-2 and MMP-9 were expressed in the majority of tumours. Our results showed a close relationship between their expression and tumour behavior. The differences observed between benign and malignant melanocytic tumours may suggest that MMP-2 and MMP-9 could be implicated in the progression of melanocytic precursor lesions to malignant melanoma, although in an inverse manner, since MMP-2 is mainly found in melanocytomas and MMP-9, on the other hand, is frequently absent in benign lesions. Therefore, our study suggests that malignancy is associated with an increase of MMP-9 and a decrease of MMP-2 expression. The association of MMP-2 with nuclear grade could indicate its role in tumour agressiveness.

Understanding MMPs regulation in melanoma provides new platforms to develop efficient therapies. For that reason, more studies concerning MMPs and their regulators are needed in order to deepen the knowledge about this enzymes, regarding their potential as prognostic markers and future therapeutic targets in several cancers, including melanoma. 


\section{Acknowledgements}

The authors thank to Mrs. Lígia Bento for expert technical assistance. he work was supported by the strategic research project PEst-OE/AGR/UI0772/2011 financed by the Foundation for Science and Technology (FCT).

\section{Author details}

Isabel Pires $^{1 *}$, Joana Gomes ${ }^{2}$, Justina Prada ${ }^{1}$, Dinora Pereira ${ }^{1}$ and Felisbina L. Queiroga ${ }^{1}$

*Address all correspondence to: ipires@utad.pt

1 CECAV, Department of Veterinary Sciences, University of Trás-os-Montes and Alto Douro, Vila Real, Portugal

2 ECVA, Department of Genetics and Biotechnology, University of Trás-os-Montes and Alto Douro, Vila Real, Portugal

\section{References}

[1] Modiano JF, Ritt MG, Wojcieszyn J. The Molecular Basis of Canine Melanoma: Pathogenesis and Trends in Diagnosis and Therapy. Journal of Veterinary Internal Medicine 1999;13(3): 163-74.

[2] Smith SH, Goldschmidt MH, McManus PM. A Comparative Review of Melanocytic Neoplasms. Veterinary Pathology 2002;39(6): 651-78.

[3] Sulaimon SS, Kitchell BE, Ehrhart EJ. Immunohistochemical Detection of Melanoma-specific Antigens in Spontaneous Canine Melanoma. Journal of Comparative Pathology 2002;127(2-3): 162-8.

[4] Malaponte G, Zacchia A, Bevelacqua Y, Marconi A, Perrotta R, Mazzarino MC, Cardile V, Stivala F. Co-regulated expression of matrix metalloproteinase-2 and transforming growth factor-beta in melanoma development and progression. Oncology Reports 2010;24(1): 81-7.

[5] Hofmann UB, Houben R, Bröcker E-B, Becker JC. Role of matrix metalloproteinases in melanoma cell invasion. Biochimie 2005;87(3-4): 307-14.

[6] Kondratiev S, Gnepp DR, Yakirevich E, Sabo E, Annino DJ, Rebeiz E, Laver NV. Expression and prognostic role of MMP2, MMP9, MMP13, and MMP14 matrix metalloproteinases in sinonasal and oral malignant melanomas. Human Pathology 2008;39(3): 337-43. 
[7] Koenig A, Wojcieszyn J, Weeks BR, Modiano JF. Expression of S100a, Vimentin, NSE, and Melan A/MART-1 in Seven Canine Melanoma Cell Lines and Twenty-nine Retrospective Cases of Canine Melanoma. Veterinary Pathology 2001;38(4): 427-35.

[8] Aina $\mathrm{OH}$, Maeda $\mathrm{Y}$, Harrison $\mathrm{M}$, Zwingenberger AL, Walker NJ, Lam KS, Kent MS. Canine malignant melanoma alpha-3 integrin binding peptides. Veterinary Immunology and Immunopathology 2011;143(1-2): 11-9.

[9] Hofmann UB, Westphal JR, Waas ET, Zendman AJ, Cornelissen IM, Ruiter DJ, van Muijen GN. Matrix metalloproteinases in human melanoma cell lines and xenografts: increased expression of activated matrix metalloproteinase-2 (MMP-2) correlates with melanoma progression. British Journal of Cancer 1999;81(5): 774-82.

[10] Moretti RM, Montagnani Marelli M, Mai S, Limonta P. Gonadotropin-releasing hormone agonists suppress melanoma cell motility and invasiveness throught the inhibition of a3 integrin and MMP-2 expression and activity. International Journal of Oncology 2008;33(2): 405-13.

[11] El-Shabrawi Y, Ardjomand N, Radner H, Ardjomand N. MMP-9 is predominantly expressed in epithelioid and not spindle cell uveal melanoma. The Journal of Pathology 2001;194(2): 201-6.

[12] Todoroff RJ, Brodey RS. Oral and pharyngeal neoplasia in the dog: a retrospective survey of 361 cases. Journal of the American Veterinary Medical Association 1979;175(6): 567-71.

[13] Vail DM, Thamm DH. Spontaneously Occurring Tumors in Companion Animals as Models for Drug Development. In: Teicher BA, Andrews PA. (eds.) Cancer Drug Discovery and Development:Anticancer Drug Development Guide: Preclinical Screening, Clinical Trials, and Approval. Totowa, NJ: Humana Press Inc.; 2004. p 259-84.

[14] Bergman PJ, Camps-Palau MA, McKnight JA, Leibman NF, Craft DM, Leung C, Liao J, Riviere I, Sadelain M, Hohenhaus AE, Gregor P, Houghton AN, Perales MA, Wolchok JD. Development of a xenogeneic DNA vaccine program for canine malignant melanoma at the Animal Medical Center. Vaccine 2006;24(21): 4582-5.

[15] Paoloni M, Khanna C. Translation of new cancer treatments from pet dogs to humans. Nature Reviews Cancer 2008;8(2): 147-56.

[16] Chaudhary A, Singh M, Bharti A, Asotra K, Sundaram S, Mehrotra R. Genetic polymorphisms of matrix metalloproteinases and their inhibitors in potentially malignant and malignant lesions of the head and neck. Journal of Biomedical Science 2010;17(10). 
[17] Gialeli C, Theocharis AD, Karamanos NK. Roles of matrix metalloproteinases in cancer progression and their pharmacological targeting. FEBS Journal 2011;278(1): 16-27.

[18] Kessenbrock K, Plaks V, Werb Z. Matrix Metalloproteinases: Regulators of the Tumor Microenvironment. Cell 2010;141(1): 52-67.

[19] Björklund M, Koivunen E. Gelatinase-mediated migration and invasion of cancer cells. Biochimica et Biophysica Acta (BBA) - Reviews on Cancer 2005;1755(1): 37-69.

[20] Handsley MM, Edwards DR. Metalloproteinases and their inhibitors in tumor angiogenesis. International Journal of Cancer 2005;115(6): 849-60.

[21] Joyce JA, Pollard JW. Microenvironmental regulation of metastasis. Nature Reviews Cancer 2009;9(4): 239-52.

[22] Foda HD, Zucker S. Matrix metalloproteinases in cancer invasion, metastasis and angiogenesis. Drug Discovery Today 2001;6(9): 478-82.

[23] Szabo KA, Ablin RJ, Singh G. Matrix metalloproteinases and the immune response. Clinical and Applied Immunology Reviews 2004;4(5): 295-319.

[24] Cauwe B, Van den Steen PE, Opdenakker G. The biochemical, biological, and pathological kaleidoscope of cell surface substrates processed by matrix metalloproteinases. Critical Reviews in Biochemistry and Molecular Biology 2007;42: 113-85.

[25] Yoon S-O, Park S-J, Yun C-H, Chung A-S. Roles of matrix metalloproteinases in tumor metastasis and angiogenesis. Journal of Biochemistry and Molecular Biology 2003;36(1): 128-37.

[26] Mannello F, Medda V. Nuclear localization of Matrix metalloproteinases. Progress in Histochemistry and Cytochemistry 2012;47(1): 27-58.

[27] López-Otín C, Palavalli LH, Samuels Y. Protective roles of matrix metalloproteinases: From mouse models to human cancer. Cell Cycle 2009;8(22): 3657-62.

[28] Sternlicht MD, Werb Z. How matrix metalloproteinases regulate cell behavior. Cell and Developmental Biology 2001;17: 463-516.

[29] Bergman RL. Matrix Metalloproteinases 2 and 9 in Normal Canine Cerebrospinal Fluid. Master thesis. Faculty of the Virginia Polytechnic Institute and State University; 2001.

[30] Tonti Ga, Mannello F, Cacci E, Biagioni S. Neural stem cells at the crossroads: MMPs may tell the way. The International Journal of Developmental Biology 2009;53(1): 1-17. 
[31] Folgueras AR, Pendás AM, Sánchez LM, López-Otín C. Matrix metalloproteinases in cancer: from new functions to improved inhibition strategies. The International Journal of Developmental Biology 2004;48(5-6): 411-24.

[32] Loukopoulos P, Mungall B, Straw R, Thornton J, Robinson W. Matrix metalloproteinase-2 and -9 involvement in canine tumors. Veterinary Pathology 2003;40(4): 382 - 94 .

[33] Aresu L, Giantin M, Morello E, Vascellari M, Castagnaro M, Lopparelli R, Zancanella V, Granato A, Garbisa S, Arico A, Bradaschia A, Mutinelli F, Dacasto M. Matrix metalloproteinases and their inhibitors in canine mammary tumors. BMC Veterinary Research 2011;7: 33.

[34] Biljana E, Boris V, Cena D, Veleska-stefkovska D. Matrix metalloproteinases (with accent to collagenases). Journal of Cell and Animal Biology 2011;5(7): 113-20.

[35] Visse R, Nagase H. Matrix Metalloproteinases and Tissue Inhibitors of Metalloproteinases. Circulation Research 2003;92(8): 827-39.

[36] Morelli C, Campioni K, Parolin C, Palù G, Tognon M. Activity of the matrix metalloproteinase-9 promoter in human normal and tumor cells. Journal of Cellular Physiology 2004;199(1): 126-33.

[37] Kerkelä E, Saarialho-Kere U. Matrix metalloproteinases in tumor progression: focus on basal and squamous cell skin cancer. Experimental Dermatology 2003;12(2): 109-25.

[38] Stamenkovic I. Extracellular matrix remodelling: the role of matrix metalloproteinases. The Journal of Pathology 2003;200(4): 448-64.

[39] Fingleton B. Matrix metalloproteinases as valid clinical targets. Current pharmaceutical design 2007;13(3): 333-46.

[40] Kallakury BVS, Karikehalli S, Haholu A, Sheehan CE, Azumi N, Ross JS. Increased Expression of Matrix Metalloproteinases 2 and 9 and Tissue Inhibitors of Metalloproteinases 1 and 2 Correlate with Poor Prognostic Variables in Renal Cell Carcinoma. Clinical Cancer Research 2001;7(10): 3113-9.

[41] Van den Steen PE, Dubois B, Nelissen I, Rudd PM, Dwek RA, Opdenakker G. Biochemistry and Molecular Biology of Gelatinase B or Matrix metalloproteinase-9 (MMP-9). Critical reviews in biochemistry and molecular biology 2002;37(6): 375-536.

[42] Johansson N. Matrix metalloproteinases in tumor invasion. Cellular and Molecular Life Sciences 2000;57(1): 5-15.

[43] Deryugina E, Quigley J. Matrix metalloproteinases and tumor metastasis. Cancer and Metastasis Reviews 2006;25(1): 9-34. 
[44] Stamenkovic I. Matrix metalloproteinases in tumor invasion and metastasis. Seminars in Cancer Biology 2000;10(6): 415-33.

[45] Gentilini F, Calzolari C, Turba ME, Agnoli C, Fava D, Forni M, Bergamini PF. Prognostic value of serum vascular endothelial growth factor (VEGF) and plasma activity of matrix metalloproteinase (MMP) 2 and 9 in lymphomaaffected dogs. Leukemia Research 2005;29(11): 1263-9.

[46] Bergers G, Brekken R, McMahon G, Vu TH, Itoh T, Tamaki K, Tanzawa K, Thorpe P, Itohara S, Werb Z, Hanahan D. Matrix metalloproteinase-9 triggers the angiogenic switch during carcinogenesis. Nature Cell Biology 2000;2(10): 737-44.

[47] Kawai K, Uetsuka K, Doi K, Nakayama H. The Activity of Matrix Metalloproteinases (MMPs) and Tissue Inhibitors of Metalloproteinases (TIMPs) in Mammary Tumors of Dogs and Rats. Journal of Veterinary Medical Science 2006;68(2): 105-11.

[48] Turpeenniemi-Hujanen T. Gelatinases (MMP-2 and -9) and their natural inhibitors as prognostic indicators in solid cancers. Biochimie 2005;87(3-4): 287-97.

[49] Docampo M-J, Cabrera J, Rabanal RM, Bassols A. Expression of matrix metalloproteinase-2 and -9 and membrane-type 1 matrix metalloproteinase in melanocytic tumors of dogs and canine melanoma cell lines. American Journal of Veterinary Research 2011;72(8): 1087-96.

[50] Miya K, Misumi K, Miyoshi N, Arai K, Fujiki M, Kubota C, Sakamoto H. Interpreting Gelatinase Activity in Tumor Tissue and Serum as a Prognostic Marker of Naturally Developing Canine Tumors. Journal of Veterinary Medical Science 2005;67(8): 769-75.

[51] Nakaichi M, Yunuki T, Okuda M, Une S, Taura Y. Activity of matrix metalloproteinase-2 (MMP-2) in canine oronasal tumors. Research in Veterinary Science 2007;82(2): 271-9.

[52] Loukopoulos P, O'Brien T, Ghoddusi M, Mungall BA, Robinson WF. Characterisation of three novel canine osteosarcoma cell lines producing high levels of matrix metalloproteinases. Research in Veterinary Science 2004;77(2): 131-41.

[53] Hofmann UB, Westphal JR, van Muijen GNP, Ruiter DJ. Matrix Metalloproteinases in Human Melanoma. Journal of Investigative Dermatology 2000;115(3): 337-44.

[54] Li N, Mangini J, Bhawan J. New prognostic factors of cutaneous melanoma: a review of the literature. Journal of Cutaneous Pathology 2002;29(6): 324-40. 
[55] Redondo P, Lloret P, Idoate M, Inoges S. Expression and serum levels of MMP-2 and MMP-9 during human melanoma progression. Clinical and Experimental Dermatology 2005;30(5): 541-5.

[56] Simonetti O, Lucarini G, Brancorsini D, Nita P, Bernardini ML, Biagini G, Offidani A. Immunohistochemical expression of vascular endothelial growth factor, matrix metalloproteinase 2, and matrix metalloproteinase 9 in cutaneous melanocytic lesions. Cancer 2002;95(9): 1963-70.

[57] Väisänen AH, Kallioinen M, Turpeenniemi-Hujanen T. Comparison of the prognostic value of matrix metalloproteinases 2 and 9 in cutaneous melanoma. Human Pathology 2008;39(3): 377-85.

[58] Béliveau A, Bérubé M, Rousseau A, Pelletier G, Guérin SL. Expression of Integrin alpha5beta1 and MMPs Associated with Epithelioid Morphology and Malignancy of Uveal Melanoma. Investigative Ohpthalmology \& Visual Science 2000;41(8): 2363-72.

[59] Bérubé M, Deschambeault A, Boucher M, Germain L, Petitclerc E, Guérin SL. MMP-2 expression in uveal melanoma: differential activation status dictated by the cellular environment. Molecular Vision 2005;11: 1101-11.

[60] Kim HK, Chae SW, Woo KI, Kim YD. Expression of matrix metalloproteinase (MMP)-2, MMP-9, and tissue inhibitor of MMP (TIMP)-1 in conjunctival melanomas and clinical implications. Japanese Journal of Ophthalmology 2010;54(3): 221-6.

[61] Lai K, Conway RM, Crouch R, Jager MJ, Madigan MC. Expression and distribution of MMPs and TIMPs in human uveal melanoma. Experimental Eye Research 2008;86(6): 936-41.

[62] Sahin A, Kiratli H, Soylemezoglu F, Tezel GG, Bilgic S, Saracbasi O. Expression of Vascular Endothelial Growth Factor-A, Matrix Metalloproteinase-9, and Extravascular Matrix Patterns and Their Correlations with Clinicopathologic Parameters in Posterior Uveal Melanomas. Japanese Journal of Ophthalmology 2007;51(5): 325-31.

[63] Goldschmidt MH, Dunstan R, Stannard, A. Histological classification of epithelial and melanocytic tumors of the skin of domestic animals. Washington: American Registry of Pathology; 1998.

[64] Queiroga FL, Pires I, Parente M, Gregorio H, Lopes CS. COX-2 overexpression correlates with VEGF and tumour angiogenesis in canine mammary cancer. The Veterinary Journal 2010;189(1): 77-82.

[65] Ramos-Vara JA, Beissenherz ME, Miller MA, Johnson GC, Pace LW, Fard A, Kottler SJ. Retrospective study of 338 canine oral melanomas with clinical, 
histologic, and immunohistochemical review of 129 cases. Veterinary Pathology 2000;37(6): 597-608.

[66] Herlyn M, Clark WH, Rodeck U, Mancianti ML, Jambrosic J, Koprowski H. Biology of tumor progression in human melanocytes. Laboratory Investigation 1987;56(5): 461-74.

[67] Clark WH, Jr., Elder DE, Guerry Dt, Epstein MN, Greene MH, Van Horn M. A study of tumor progression: the precursor lesions of superficial spreading and nodular melanoma. Human Pathology 1984;15(12): 1147-65.

[68] Marino DJ, Matthiesen DT, Stefanacci JD, Moroff SD. Evaluation of dogs with digit masses: 117 cases (1981-1991). Journal of the American Veterinary Medical Association 1995;207(6): 726-8.

[69] Theon AP, Rodriguez C, Madewell BR. Analysis of prognostic factors and patterns of failure in dogs with malignant oral tumors treated with megavoltage irradiation. Journal of the American Veterinary Medical Association 1997;210(6): 778-84.

[70] Bergman PJ. Canine oral melanoma. Clinical Techniques in Small Animal Practice 2007;22(2): 55-60.

[71] Gomes J, Queiroga FL, Prada J, Pires I. Study of c-kit immunoexpression in canine cutaneous melanocytic tumors. Melanoma Research 2012;22(3): 195-201.

[72] Pires I, Garcia A, Prada J, Queiroga FL. COX-1 and COX-2 expression in canine cutaneous, oral and ocular melanocytic tumours. Journal of Comparative Pathology 2010;143(2-3): 142-9.

[73] Pires I, Prada J, Coelho L, Garcia A, Queiroga FL. Tumour-Associated Macrophages (TAMs) and Cox-2 Expression in Canine Melanocytic Lesions. In: Murph M. (ed.) Melanoma in the Clinic - Diagnosis, Management and Complications of Malignancy. Rijeka: InTech; 2011.

[74] Banerji A, Chakrabarti J, Mitra A, Chatterjee A. Effect of curcumin on gelatinase A (MMP-2) activity in B16F10 melanoma cells. Cancer Letters 2004;211(2): 235-42.

[75] Banerji A, Das S, Chatterjee A. Culture of human A375 melanoma cells in the presence of fibronectin causes expression of MMP-9 and activation of MMP-2 in culture supernatants. Journal of Environmental Pathology, Toxicology and Oncology 2008;27(2): 135-45.

[76] Akhavan MM, Karimi M, Ghodrati M, Falahtpishe H. AT1 receptors activation enhances the expression of MMP-2, MMP-13 and VEGF but not MMP-9 in B16F10 melanoma cells. Pakistan Journal of Biological Sciences 2011;14(17): 821-30. 
[77] Hofmann UB, Westphal JR, Zendman AJ, Becker JC, Ruiter DJ, van Muijen GN. Expression and activation of matrix metalloproteinase-2 (MMP-2) and its co-localization with membrane-type 1 matrix metalloproteinase (MT1-MMP) correlate with melanoma progression. The Journal of Pathology 2000;191(3): 245-56.

[78] Ohnishi Y, Tajima S, Ishibashi A. Coordinate expression of membrane typematrix metalloproteinases-2 and 3 (MT2-MMP and MT3-MMP) and matrix metalloproteinase-2 (MMP-2) in primary and metastatic melanoma cells. Eur J Dermatol 2001;11(5): 420-3.

[79] Ohnishi Y, Tajima S, Ishibashi A. Coordinate expression of membrane typematrix metalloproteinases-2 and 3 (MT2-MMP and MT3-MMP) and matrix metalloproteinase-2 (MMP-2) in primary and metastatic melanoma cells. European Journal of Dermatology 2001;11(5): 420-3.

[80] Spangler WL, Kass PH. The histologic and epidemiologic bases for prognostic considerations in canine melanocytic neoplasia. Veterinary Pathology 2006;43(2): 136-49.

[81] Vaisanen A, Tuominen H, Kallioinen M, Turpeenniemi-Hujanen T. Matrix metalloproteinase-2 (72 kD type IV collagenase) expression occurs in the early stage of human melanocytic tumour progression and may have prognostic value. The Journal of Pathology 1996;180(3): 283-9.

[82] Redondo P, Lloret P, Idoate M, Inoges S. Expression and serum levels of MMP-2 and MMP-9 during human melanoma progression. Journal of Clinical \& Experimental Dermatology 2005;30(5): 541-5.

[83] Vaisanen A, Kallioinen M, Taskinen PJ, Turpeenniemi-Hujanen T. Prognostic value of MMP-2 immunoreactive protein (72 $\mathrm{kD}$ type $\mathrm{IV}$ collagenase) in primary skin melanoma. The Journal of Pathology 1998;186(1): 51-8.

[84] Vaisanen A, Kallioinen M, von Dickhoff K, Laatikainen L, Hoyhtya M, Turpeenniemi-Hujanen T. Matrix metalloproteinase-2 (MMP-2) immunoreactive protein--a new prognostic marker in uveal melanoma? The Journal of Pathology 1999;188(1): 56-62.

[85] Baltazar-Rodriguez L, Anaya-Ventura A, Andrade-Soto M, Monrroy-Guizar E, Bautista-Lam J, Jonguitud-Olguin G. Polymorphism in the matrix metalloproteinase-2 gene promoter is associated with cervical neoplasm risk in Mexican women. Biochemical Genetics 2008;46(3-4): 137-44.

[86] Chen T, Zhu J. Evaluation of EMMPRIN and MMP-2 in the prognosis of primary cutaneous malignant melanoma. Medical Oncology 2010;27(4): 1185-91.

[87] Desch A, Strozyk EA, Bauer AT, Huck V, Niemeyer V, Wieland T, Schneider SW. Highly Invasive Melanoma Cells Activate the Vascular Endothelium via 
an MMP-2/Integrin alphavbeta5-Induced Secretion of VEGF-A. American Journal of Pathology 2012;181(2): 693-705.

[88] Sahin A, Kiratli H, Tezel GG, Soylemezoglu F, Bilgic S. Expression of vascular endothelial growth factor a, matrix metalloproteinase 9 and extravascular matrix patterns in iris and ciliary body melanomas. Ophthalmic Research 2007;39(1): 40-4.

[89] Chen Y, Huang L, Yu J. Evaluation of heparanase and matrix metalloproteinase-9 in patients with cutaneous malignant melanoma. Journal of Dermatology 2012;39(4): 339-43.

[90] van den Oord JJ, Paemen L, Opdenakker G, de Wolf-Peeters C. Expression of gelatinase $\mathrm{B}$ and the extracellular matrix metalloproteinase inducer EMMPRIN in benign and malignant pigment cell lesions of the skin. American Journal of Pathology 1997;151(3): 665-70.

[91] Kong L, Fang W, Zhong H, Heng W, Li Y, Wu B. Controlled expression of matrix metalloproteinase 9 promotes expression of invasive phenotype of human melanoma cells. Beijing Da Xue Xue Bao 2003;35(1): 7-11.

[92] Bodey B, Bodey B, Jr., Siegel SE, Kaiser HE. Matrix metalloproteinase expression in malignant melanomas: tumor-extracellular matrix interactions in invasion and metastasis. In Vivo 2001;15(1): 57-64.

[93] MacDougall JR, Bani MR, Lin Y, Muschel RJ, Kerbel RS. 'Proteolytic switching': opposite patterns of regulation of gelatinase $\mathrm{B}$ and its inhibitor TIMP-1 during human melanoma progression and consequences of gelatinase B overexpression. British Journal of Cancer 1999;80(3-4): 504-12.

[94] MacDougall JR, Bani MR, Lin Y, Rak J, Kerbel RS. The 92-kDa gelatinase B is expressed by advanced stage melanoma cells: suppression by somatic cell hybridization with early stage melanoma cells. Cancer Research 1995;55(18): 4174-81.

[95] Sil H, Sen T, Chatterjee A. Fibronectin-integrin (alpha5beta1) modulates migration and invasion of murine melanoma cell line B16F10 by involving MMP-9. Oncology Research 2011;19(7): 335-48.

[96] Aksenenko MB, Gyrylova SN, Ruksha TG. Changes in the Levels of NCadherin and PCNA in Skin Melanoma Cells Are Mediated through Matrix Metalloproteinase 9. Bulletin of Experimental Biology and Medicine 2012;153(3): 364-6.

[97] Mehrotra R, Pandya S, Chaudhary A, Kumar M, Singh M. Prevalence of oral pre-malignant and malignant lesions at a tertiary level hospital in Allahabad, India. Asian Pacific Journal of Cancer Prevention 2008;9(2): 263-65. 
